\title{
IMPLEMENTASI CLOUD COMPUTING SEBAGAI RADIUS SERVER PADA JARINGAN INTERNET ROUTER MIKROTIK
}

\author{
${ }^{1}$ Ismail Puji Saputra ${ }^{2}$ Ridwan Yusuf ${ }^{3}$ Usep Saprudin \\ ${ }^{1}$ ISMAIL PUJI SAPUTRA, Universitas Muhammadiyah Metro, ismailpujisaputra@gmail.com \\ ${ }^{2}$ RIDWAN YUSUF, STMIK Dharma Wacana, kinglotto@yahoo.com \\ ${ }^{3}$ USEP SAPRUDIN, STMIK Dharma Wacana, usepkreatif@gmail.com
}

\begin{abstract}
Abstrak
Banyaknya pengguna internet pada suatu tempat atau instansi menimbulkan sebuah antrian yang menyebabkan sulitnya pengguna dalam mengakses internet. Berdasarkan masalah tersebut penulis mengimplementasikan cloud computing sebagai radius server pada jaringan internet dengan menggunakan Router MikroTik sebagai alat manajemen bandwith, RADIUS (Remote Authentication Dial-In User Service) server akan dibangun didalam server Ubuntu dengan memanfaatkan service cloud computing dari AWS (Amazon WEB Service), selain sebagai RADIUS server, Dengan adanya RADIUS server yang dibangun dengan cloud computing dan Router MikroTik stabilitas jaringan internet pada suatu tempat atau instansi menjadi lebih baik dan proses manajemen pengguna menjadi mudah.
\end{abstract}

\section{Kata Kunci : Cloud computing, RADIUS Server, Jaringan Internet, MikroTik}

\section{Pendahuluan}

Internet menjadi sebuah kebutuhan yang mendasar. Menurut survey yang dilakukan oleh APJII (Asosiasi Penyelenggara Jasa Internet Indonesia) penetrasi pengguna internet di indonesia pada tahun 2018 sekitar $\pm 171,17$ juta jiwa atau sekitar $64,8 \%$ dari total populasi penduduk Indonesia.

Banyaknya pengguna internet pada suatu tempat menimbulkan sebuah antrian yang menyebabkan sulitnya pengguna dalam mengakses internet, hal tersebut terjadi karena tidak adanya otorisasi sehingga pembagian bandwith ke pengguna menjadi tidak merata, untuk itu diperlukan sebuah manajemen bandwith agar internet berjalan dengan lancar. Untuk mengatur pembagian bandwith dibutuhkan alat yang disebut MikroTik Routerboard yang memiliki fitur hotspot dan usermanager yang mampu melakukan autentikasi dan otorisasi.

Fitur MikroTik hotspot perlu dimaksimalkan dengan menggunakan fitur MikroTik remote authentication dial-in user service (RADIUS) client. RADIUS client memungkinkan MikroTik Routerboard terhubung dengan RADIUS server yang dapat melakukan autentikasi, otorisasi dan akuntansi.

RADIUS server akan diinstal pada server khusus diluar dari Routerboard sehingga proses authentikasi dan authorisasi tidak dilakukan di Routerboard sehingga storage dan CPU load pada Routerboard tetap stabil. RADIUS server akan meminta identitas user untuk dicocokan dengan data yang ada di dalam database sebelum user terkoneksi ke jaringan, untuk memaksimalkan fungsinya memerlukan aplikasi web untuk mempermudah operator dalam memanajamen akun dan bandwith user, selain diinstal freeradius dan MySQL maka RADIUS server juga akan diinstal hypertext processor (PHP) dengan apache untuk menjalankan aplikasi web. Server ini akan dibangun memanfaatkan teknologi cloud computing (komputasi awan) yang menyediakan sumberdaya dengan harga sewa yang murah.

\section{Metode penelitian}

Metode penelitian adalah cara, prosedur, konsep atau aturan yang digunakan dalam mengumpulkan data guna diteliti. Berikut ini adalah langkah-langkah yang dilakukan. 
Berikut ini adalah metodologi penelitian yang akan dilakukan dalan Implementasi Cloud Computing Sebagai Radius Server Pada Jaringan Internet Router Mikrotik.

\section{Flowchart Metodologi Penelitian}

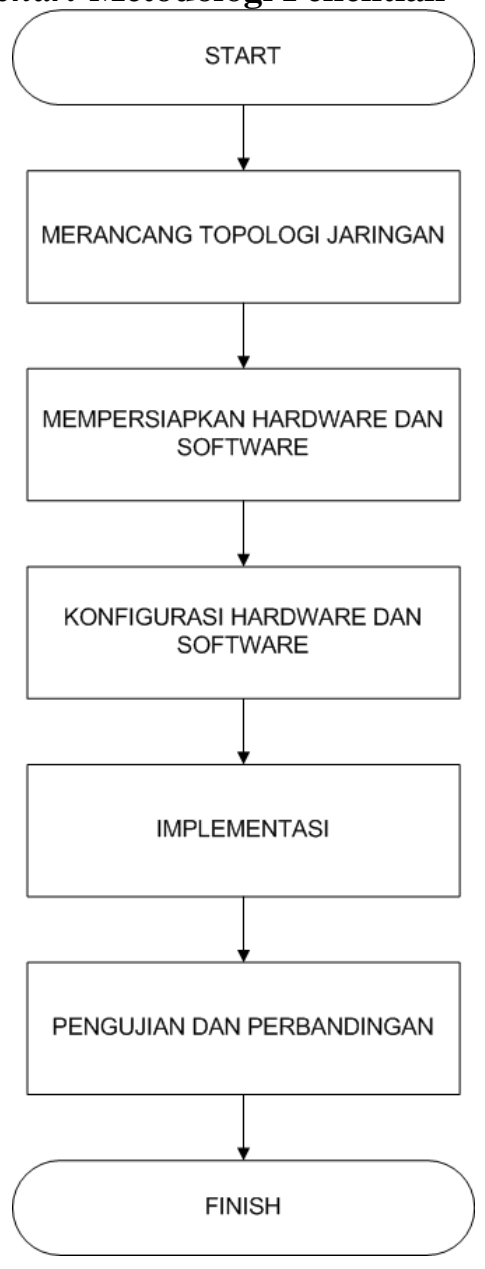

2. Topologi Jaringan Yang Akan Dibangun

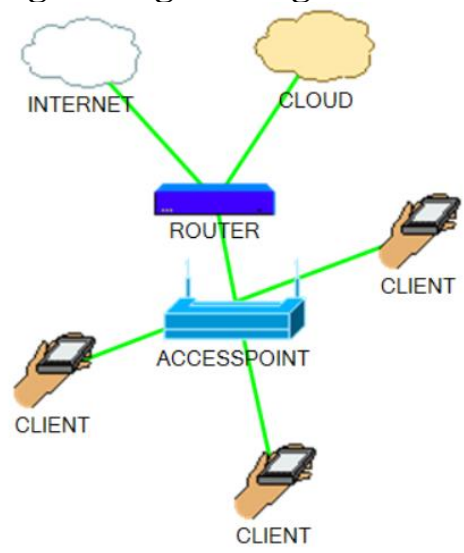

\section{Tabel Kebutuhan Hardware}

Berikut ini adalah tabel hardware yang dibutuhkan dalam membangun infrastruktur jaringan dalam penelitian ini.

\begin{tabular}{|c|c|c|c|}
\hline No & HARDWARE & JUMLAH & SPESIFIKASI \\
\hline 1 & $\begin{array}{l}\text { Routerboard MikroTik } \\
\text { RB941-2nD-TC }\end{array}$ & 1 unit & $\begin{array}{l}\text { Main Storage: } 16 \mathrm{MB} \\
\text { RAM: } 32 \mathrm{MB} \\
\text { LAN Port : } 4\end{array}$ \\
\hline 2 & $\begin{array}{l}\text { Access point Tenda } \\
\text { N301 }\end{array}$ & 1 unit & $\begin{array}{l}\text { Frekuensi: } 2.412 \mathrm{GHz}- \\
2.472 \mathrm{GHz} \\
\text { Antenna: } 2 \text { fixed } 5 \mathrm{dbi} \text { Omni } \\
\text { Directional antenas } \\
\text { WAN port: } 1 \text { 10/100Mbps } \\
\text { Protocol: IEEE } 802.3 / 3 \mathrm{U} \text { IEEE } \\
802.11 \mathrm{n} / \mathrm{g} / \mathrm{b}\end{array}$ \\
\hline 3 & Konektor RJ45 & $1 \mathrm{pcs}$ & $\begin{array}{l}\text { Tipe: CAT } 5 \text { E } \\
\text { Speed: } 1 \text { Gbit/s }\end{array}$ \\
\hline 4 & Kabel UTP & \pm 20 meter & $\begin{array}{l}\text { Tipe: CAT5E } \\
\text { Speed: } 1 \text { Gbit/s }\end{array}$ \\
\hline 5 & \begin{tabular}{|l|} 
LAPTOP \\
\end{tabular} & 1 unit & $\begin{array}{l}\text { RAM } 8 \text { Gb } \\
\text { Prosesor Core i7 } \\
\text { Hardisk 50Gb }\end{array}$ \\
\hline
\end{tabular}

\section{Tabel Kebutuhan Software}

Berikut ini adalah tabel software yang dibutuhkan dalam membangun infrastruktur jaringan dalam penelitian ini.

\begin{tabular}{|c|l|l|}
\hline NO & \multicolumn{1}{|c|}{ SOFTWARE } & \multicolumn{1}{|c|}{ SPESIFIKASI } \\
\hline 1 & Ubuntu 16.04 LTS & SSD: 20GB \\
& & RAM: $512 \mathrm{MB}$ \\
\hline 2 & Apache & vCPU: 1 \\
\hline 3 & MySQL & Version: 2.4 .43 \\
\hline 4 & PHP & Version: 5.6 \\
\hline 5 & Oracle VM & Version: 5.6 \\
\hline 7 & Virtualbox & Version: 6.1 .10 \\
\hline 6 & RADIUS test and & Version: 4.0 .51 \\
& monitoring client & \\
\hline & & Google Chrome \\
\hline & & \\
\hline
\end{tabular}




\section{Diagram Alir Sistem}

Diagram alir sistem ini menggambarkan alur kerja dari proses autentikasi dan otorisasi dari infrastruktur jaringan yang akan dibagun. Berikut adalah gambaran proses yang akan dilalui user dari awal hingga terkoneksi ke jaringan.

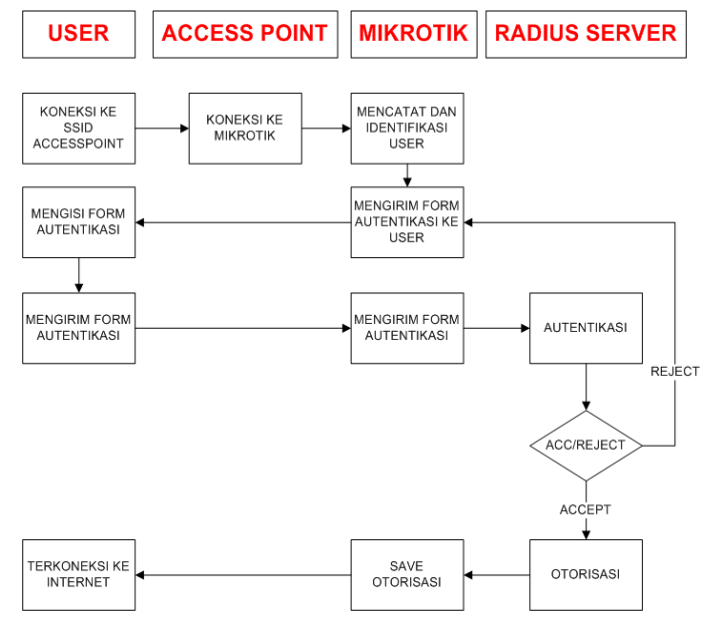

Penjelasan dari diagram alir sistem

- User melakukan koneksi ke access point.

- Access point menerima koneksi dan meneruskanya ke MikroTik.

- MikroTik mencatat user dan mengirim form autentikasi kepada user.

- User mengisi dan mengirim form autentikasi ke MikroTik.

- MikroTik meneruskan paket autentikasi ke RADIUS server.

- RADIUS server melakukan autentikasi, apabila autentikasi diterima maka user akan di otorisasi untuk mendapatkan koneksi internet dengan besaran bandwith tertentu.

- Jika autentikasi user ditolak oleh RADIUS server, maka MikroTik akan mengirimkan form autentikasi ulang kepada $u$ ser.

\section{Hasil dan Pembahasan}

pada tahapan ini akan dilakukan uji coba kepada infrastruktur jaringan yang telah dibuat. Ujicoba dilakukan dengan serangkaian test yaitu test autentikasi, otorisasi (pembagian bandwith) dan dilakukan perbandingan kecepatan proses autentikasi pada sisi user serta kecepatan query pada sisi server antara server cloud dan server non-cloud.

1. Uji coba proses autentikasi dan otorisasi.

Uji coba dilakukan dengan bandwith upload/download sebesar 600kb yang dibagikan ke 3 buah handphone, dimana setiap handphone akan diberikan 1 buah username dan password.

Berikut ini adalah topologi dalam ujicoba proses autentikasi dan otorisasi.

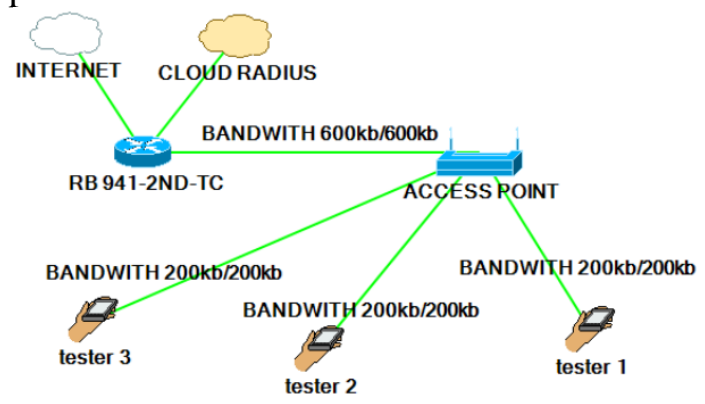

Hasil proses ujicoba autentikasi dan otorisasi

a. Proses autentikasi

Proses autentikasi dilakukan dengan cara user terkoneksi ke jaringan melalui accesspoint, user akan diarahkan ke form login untuk mengisi form login dan form akan dicocokan dengan database RADIUS server.

Berikut ini adalah proses autentikasi user.

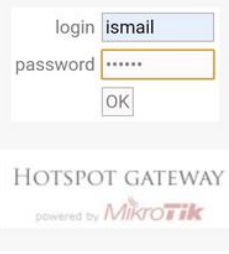

b. Proses otorisasi

Otorisasi disini adalah proses dimana user yang telah diautentikasi akan diberikan besaran bandwith tertentu, berikut ini bandwith yang diperoleh user yang tercatat dalam simple-queиe MikroTik. 
Berikut ini user yang sudah diautentikasi masuk kedalam simple-queиe secara otomatis.

Queue List
Simple Queues
\begin{tabular}{|c|c|c|c|c|c|c|c|c|}
\hline & Interface Queues & Queue Tree & Queue Types \\
\hline \# & & Name & & Target & Upload ... & Download. \\
\hline O D & S chotspot-ismail & 172.16 .0 .3 & $200 k$ & $200 k$ \\
\hline
\end{tabular}

2. Perbandingan kecepatan proses autentikasi pada sisi user dan proses kecepatan query pada sisi server cloud dan non-cloud, Proses perbandingan mengenyampingkan spesifikasi hardware dari masing-masing server. Berikut ini adalah topologi perbandingan proses autentikasi dan kecepatan query.
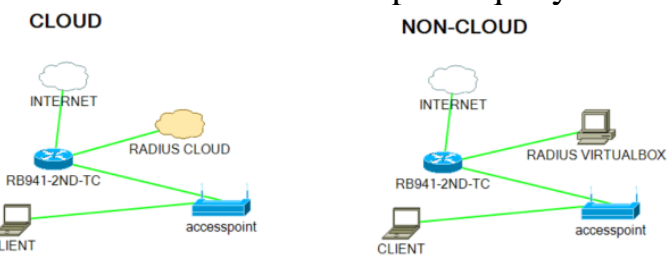

a. Uji kecepatan proses autentikasi pada user.

Pengujian dilakukan dengan membandingkan kecepatan proses login pada browser user dengan RADIUS server cloud dan non-cloud.

Berikut ini adalah contoh pengujian kecepatan proses autentikasi.

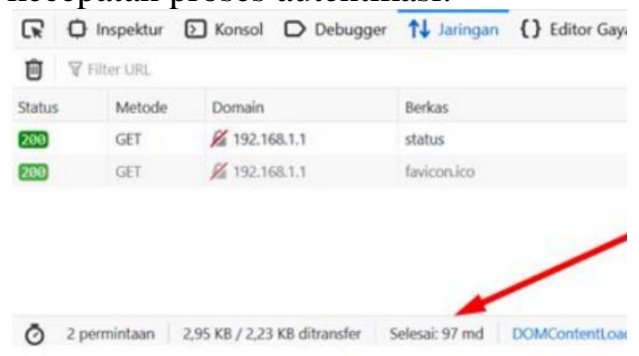

Berikut ini adalah grafik perbandingan kecepatan proses autentikasi antara server cloud dan non-cloud.

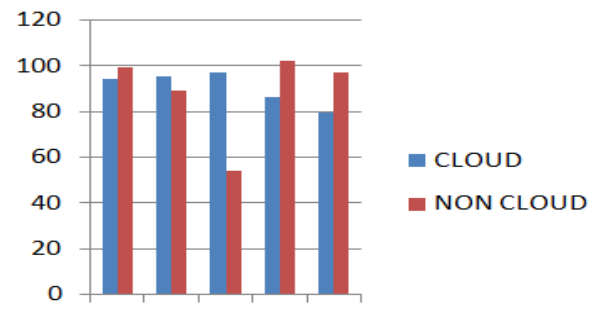

Dari grafik perbandingan didapatkan tabel perbandingan dari hasil uji kecepatan proses autentikasi disisi client. Berikut ini adalah tabel perbandingan hasil kecepatan proses autentikasi di sisi user.

\begin{tabular}{|l|l|c|}
\hline NO & KETERANGAN & WAKTU RATA-RATA \\
\hline 1 & Rata-rata waktu cloud & $90,2 \mathrm{md}$ \\
\hline 2 & Rata-rata waktu non-cloud & $88,2 \mathrm{md}$ \\
\hline \multicolumn{2}{|l|}{ Selisih( waktu cloud - waktu non cloud) } & $2 \mathrm{md}$ \\
\hline
\end{tabular}

b. Uji kecepatan proses query pada server. Proses perbandingan dilakukan dengan aplikasi RADIUS test client dengan aplikasi tersebut akan muncul waktu yang dibutuhkan dalam mengakses query yang dilakukan ke database MySQL.

Berikut ini contoh proses pengujian kecepatan query.

Response

Status: Good

Resp Time: $20 \mathrm{~ms}$

\begin{tabular}{|l|l|l|}
\hline \multicolumn{2}{|l|}{ Attribute } & Data \\
\hline Mikrotik & Mikrotik-Rate-Limit & "1024k/1024k" \\
\hline
\end{tabular}

Berikut ini adalah grafik perbandingan kecepatan query antara server cloud dan non-cloud.

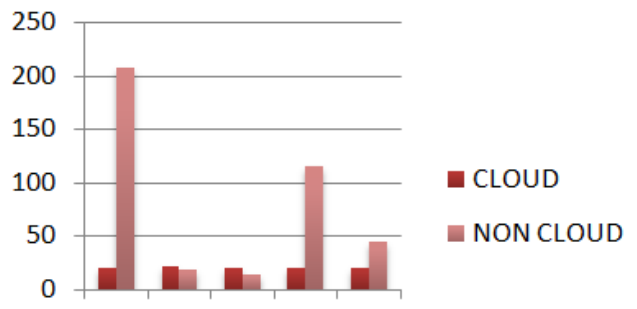

Dari grafik perbandingan didapatkan tabel perbandingan kecepatan query antara server cloud dan non-cloud.

\begin{tabular}{|l|l|c|}
\hline NO & KETERANGAN & WAKTU RATA-RATA \\
\hline 1 & $\begin{array}{l}\text { Kecepatan rata-rata query non- } \\
\text { cloud }\end{array}$ & $95,6 \mathrm{md}$ \\
\hline 2 & Kecepatan rata-rata query cloud & $20,2 \mathrm{md}$ \\
\hline \multicolumn{2}{|l|}{ Selisih( kecepatan cloud - waktu non- } \\
cloud)
\end{tabular}




\section{Kesimpulan}

Dari hasil penelitian yang telah dilakukan terdapat kesimpulan yang dapat diambil yaitu Server RADIUS yang diinstal didalam cloud computing berjalan dengan baik, Manajemen user hotspot menjadi lebih mudah dan Setelah dilakukan pengaturan bandwith menggunakan hotspot, terbukti pengguna mendapatkan bandwith yang sama.

Dibandingkan dengan server non-cloud server yang dibangun di dalam cloud memiliki beberapa kelebihan yaitu dapat digunakan di router yang berbeda jaringan dengan server RADIUS, asalkan router tersebut terkoneksi dengan internet, memiliki kecepatan akses query ke database yang lebih baik, berdasarkan percobaan yang telah dilakukan server cloud lebih cepat dengan selisih waktu 75,4 md dari server non-cloud, cloud computing tidak membutuhkan ruang server, listrik dan pendingin ruangan. dengan layanan cloud computing dari AWS Amazon hanya mengeluarkan biaya sewa $<\$ 1$ perbulan atau sekitar < Rp.15.000.,

Sedangkan kekurangan dari server cloud dibandingkan dengan server non-cloud yaitu dalam melakukan proses autentikasi Routerboard harus terkoneksi ke internet untuk dapat mengakses server RADIUS, sehingga apabila internet down proses autentikasi tidak dapat berjalan dan penelitian yang telah dilakukan proses autentikasi pada server RADIUS cloud lebih lambat sekitar 2 md daripada server RADIUS non-cloud.

\section{Daftar Pustaka}

APJII. (2018). Penetrasi dan Profil Perilaku Pengguna Internet Indonesia

Mell, Peter, and Tim Grance. "The NIST definition of cloud computing." (2011).

Husda, Nur Elfi, and Yvonne Wangdra. "Pengantar Teknologi Informasi." Jakarta: Baduose Media (2016).

Komputer, W. (2014). Mudah belajar mikrotik menggunakan metode virtualisasi. Penerbit Andi, Yogyakarta
MADCOMS, Team Kreatif. "Manajemen Sistem Jaringan Komputer dengan Mikrotik RouterOS." (2016).

Sianipar, R. H. (2015). Membangun Web dengan PHP dan MySQL Untuk Pemula dan Programmer (Vol. 1). Penerbit INFORMATIKA.

Hidayatullah, P., \& Kawistara, J. K. (2014). Pemrograman Web. Informatika Bandung.

Wicaksono, S. R dkk. "Jaringan Komputer Konsep dan Studi Kasus." Seribu Bintang, (2019).

Purbo, O. W. (2018). INTERNET-TCP/IP: KONSEP\&IMPLEMENTASI. Yogyakarta: Andi. 